\title{
Exertional hypoxia in patients without resting hypoxia is an early predictor of moderate to severe COVID-19
}

\author{
Ajay Bhasin ${ }^{1,2} \cdot$ Melissa Bregger $^{1} \cdot$ Mark Kluk $^{1,2} \cdot$ Peter Park $^{1} \cdot$ Joe Feinglass $^{3} \cdot$ Jeffrey Barsuk ${ }^{1}$
}

Received: 5 January 2021 / Accepted: 9 March 2021 / Published online: 26 March 2021

(c) Società Italiana di Medicina Interna (SIMI) 2021

\begin{abstract}
The importance of exertional hypoxia without resting hypoxia in COVID-19 is unknown and may help objectively identify high-risk patients. Interventions may be initiated earlier with sufficient lead-time between development of exertional hypoxia and other outcome measures. We performed a retrospective study of adult patients hospitalized with COVID-19 from March 1, 2020 to October 30, 2020 in an integrated academic medical system in the Chicagoland area. We analyzed patients who had daily exertional oximetry measurements taken. We defined exertional hypoxia as $\mathrm{SpO} 2<90 \%$ with ambulation. We excluded patients who had first exertional oximetry measurements or first exertional hypoxia after the use of oxygen therapies. We determined the association of exertional hypoxia without resting hypoxia with the eventual need for nasal cannula or advanced oxygen therapies (defined as high flow nasal cannula, Bi-PAP, ventilator, or extracorporeal membrane oxygenation). We also calculated the time between development of exertional hypoxia and the need for oxygen therapies. Of 531 patients included, 132 (24.9\%) had exertional hypoxia. Presence of exertional hypoxia was strongly associated with eventual use of nasal cannula (OR 4.8, 95\% CI 2.8-8.4) and advanced oxygen therapy (IRR 7.7, 95\% CI 3.4-17.5). Exertional hypoxia preceded nasal cannula use by a median $12.5 \mathrm{~h}$ [IQR 3.25, 29.25] and advanced oxygenation by $54 \mathrm{~h}$ [IQR 25, 82]. Exertional hypoxia without resting hypoxia may serve as an early, non-invasive physiologic marker for the likelihood of developing moderate to severe COVID-19. It may help clinicians triage patients and initiate earlier interventions.
\end{abstract}

Keywords COVID-19 · Exertional Hypoxia $\cdot$ Hospital Medicine $\cdot$ Respiratory physiology

\section{Introduction}

Coronavirus-induced-disease-2019 (COVID-19) has caused a pandemic with $86,003,887$ cases and $1,860,190$ deaths worldwide [1]. In our clinical experience, many inpatients with COVID-19 first exhibited hypoxia with exertion, then subsequently developed moderate to severe disease

Ajay Bhasin

Ajay.bhasin@nm.org

1 Department of Medicine, Division of Hospital Medicine, Northwestern Memorial Hospital, Feinberg School of Medicine, 211 E. Ontario, Suite 700, Chicago, IL 60611, USA

2 Department of Pediatrics, Division of Hospital Based Medicine, Ann \& Robert H Lurie Children's Hospital, Feinberg School of Medicine, Chicago, IL, USA

3 Department of Medicine, Division of General Internal Medicine and Geriatrics, Feinberg School of Medicine, Chicago, IL, USA requiring nasal cannula or more advanced oxygen therapies. Early COVID-19 induces occult lung damage, noted by peripheral ground-glass opacities on imaging [2]. We suspect patients at this stage exhibit exertional but not resting hypoxia. Exertional oximetry measurements are utilized in some emergency departments as a part of risk assessment tools for COVID-19 [3, 4], but measurement methodology is not standardized and outcomes of exertional hypoxia in absence of resting hypoxia are not known. Several studies have characterized risk factors for severe COVID-19 based on patient-specific comorbidities and laboratory data. To our knowledge, no study has evaluated exertional hypoxia in absence of resting hypoxia as a risk factor for development of moderate to severe disease. Therefore, we aimed to evaluate if exertional hypoxia is associated with COVID-19 progression. 


\section{Methods}

We performed a retrospective observational study of adults (age $\geq 18$ years) hospitalized with COVID-19 who had exertional oxygen measurements without first having resting hypoxia at Northwestern Medicine (NM) between March 1, 2020 and October 30, 2020. NM is an integrated academic medical system in the Chicagoland area with ten affiliated hospitals. We compared the associations between patients with and without exertional hypoxia and the use of nasal cannula (NC) or advanced oxygenation therapy [defined as high flow nasal cannula (HFNC), bi-level positive airway pressure (BiPAP), mechanical ventilation (vent) or extracorporeal membrane oxygenation (ECMO)]. We evaluated the time from the measurement of exertional hypoxia to initiation of $\mathrm{NC}$ and advanced oxygenation therapies. This study was approved by the Northwestern University Institutional Review Board.

\section{Procedure}

We queried the Northwestern University Enterprise Data Warehouse (EDW) for all adult patients hospitalized with COVID-19 (by ICD-10 code). The EDW is a complete database of clinical data extracted from the electronic medical records at NM. Hospital protocols within NM recommend that all patients with COVID-19 have once daily exertional oximetry screening with the 6-min walk test, if and as able to participate. Any exertional oxygen saturation below $90 \%$ was considered hypoxia. All measurements were performed by a bedside nurse within the patient's room due to safety measures in place due to the pandemic. Oxygen therapy outcomes included need for NC, HFNC, BiPAP, vent, and ECMO. Date and time of exertional oxygen measurements and initiation of all oxygen therapy outcomes were recorded. We excluded patients in whom oxygen therapy outcomes occurred before first exertional pulse oximetry measurement or first exertional hypoxia and those still hospitalized at the end of the study period.

Patient demographic and clinical data on admission including age, sex, race and ethnicity, body mass index (BMI), D-dimer, ferritin, and c-reactive protein (CRP) were recorded. The EDW query also included all ICD-10 codes for pre-existing chronic conditions. The Charlson comorbidity index for each patient was calculated based on admission ICD-10 codes to account for severity of illness at admission. For patients with multiple admissions, only data and outcomes during a chronologically first 'index' encounter were evaluated. Age, BMI, Charlson, D-dimer, $\mathrm{CRP}$, and ferritin values were categorized for ease of interpretation. Time between exertional hypoxia and use of NC or advanced oxygen therapies was measured using the first occurrence of the oxygen therapy outcome.

\section{Analysis}

Chi-square tests were used to evaluate bivariate associations between demographic and clinical variables and the proportion of patients with exertional hypoxia and subsequent use of nasal cannula or advanced oxygenation therapy. We used multivariable logistic regression of the likelihood of nasal cannula to test the significance of exertional hypoxia because NC occurred in $13 \%$ of patients. We used multivariable Poisson regression of the likelihood of advanced oxygen therapy to test the significance of exertional hypoxia because advanced oxygenation occurred in $6 \%$ of patients $[5,6]$. We controlled for patients' demographic and clinical characteristics including age, sex, race and ethnicity, BMI, and Charlson score, plus laboratory values that were significant at $p<0.1$ in bivariate associations. We performed sensitivity analyses substituting specific ICD-10 diagnoses including atrial fibrillation, coronary artery disease, congestive heart failure, diabetes mellitus, connective tissue disease, chronic obstructive pulmonary disease, hepatic failure with encephalopathy, human immunodeficiency virus, hypertension, leukemia or lymphoma, other immunodeficiencies, peripheral arterial disease, renal disease, solid tumor, and transplant in place of the Charlson score. R (3.6.1, Vienna, Austria) was used for analysis.

\section{Results}

Our study included 531 patients with exertional oximetry measurements prior to oxygenation outcomes. Of these, 132 patients $(24.9 \%)$ had exertional hypoxia without resting hypoxia. NC was eventually required by $28.8 \%$ of patients with exertional hypoxia, compared to $8.0 \%$ of patients without it $\left(p=2.4 \times 10^{-9}\right)$. Advanced oxygenation therapy was eventually required by $18.9 \%$ of patients with exertional hypoxia, compared to $2.3 \%$ without it $\left(p=4.6 \times 10^{-11}\right)$. Demographic and clinical variables are listed in Table 1. Characteristics of patients with exertional hypoxia are listed in Table 2.

Multivariable logistic and Poisson regression results confirmed that the presence of exertional hypoxia was strongly associated with the eventual use of NC (OR 4.8, 95\% CI 2.8-8.4) and advanced oxygenation (IRR 7.7, 95\% CI 3.4-17.5); Table 3. Results were unchanged in the sensitivity analysis. Exertional hypoxia preceded NC use by a median $12.5 \mathrm{~h}$ [IQR 3.25, 29.25] and advanced oxygenation therapies by $54 \mathrm{~h}$ [IQR 25, 82]. 
Table 1 Percentage of inpatients with COVID-19 with each demographics and clinical variable who underwent exertional oximetry and developed need for oxygen therapies

\begin{tabular}{|c|c|c|c|}
\hline Characteristics & $\begin{array}{l}\text { All Patients } \\
(n=531) \% *\end{array}$ & $\begin{array}{l}\text { Nasal Cannula } \\
(n=70) \% *\end{array}$ & $\begin{array}{l}\text { Advanced Oxygenation } \\
\text { Therapy }(n=34) \% *\end{array}$ \\
\hline Exertional Hypoxia Present ${ }^{a}$ & 24.9 & 7.2 & 4.7 \\
\hline \multicolumn{4}{|l|}{ Age (years) ${ }^{b}$} \\
\hline$<50$ & 32.0 & 2.4 & 1.3 \\
\hline $50-59$ & 18.6 & 2.8 & 1.1 \\
\hline $60-69$ & 23.0 & 3.8 & 2.4 \\
\hline$\geq 70$ & 26.4 & 4.1 & 1.5 \\
\hline \multicolumn{4}{|l|}{ Sex } \\
\hline Male & 50.1 & 6.2 & 4.0 \\
\hline Female & 49.9 & 7.0 & 2.4 \\
\hline \multicolumn{4}{|l|}{ Race and Ethnicity } \\
\hline Non-Hispanic White & 33.9 & 5.8 & 2.1 \\
\hline Hispanic or Latino & 34.7 & 4.0 & 1.5 \\
\hline Black or African American & 21.7 & 2.1 & 1.9 \\
\hline Other Races and ethnicities & 9.8 & 1.3 & 0.9 \\
\hline \multicolumn{4}{|l|}{ BMI $\left(\mathrm{kg} / \mathrm{m}^{2}\right)^{\mathrm{c}}$} \\
\hline$<24.9$ & 21.8 & 3.0 & 1.5 \\
\hline $25.0-29.9$ & 29.2 & 3.4 & 1.3 \\
\hline $30.0-39.9$ & 30.5 & 3.8 & 1.7 \\
\hline$\geq 40$ & 10.0 & 2.1 & 1.5 \\
\hline Unmeasured & 8.5 & 0.9 & 0.4 \\
\hline \multicolumn{4}{|l|}{ Admission D-Dimer (ng/mL) } \\
\hline 0-999 & 53.1 & 7.0 & 3.6 \\
\hline$\geq 1000$ & 5.8 & 0.8 & 0.8 \\
\hline Unmeasured & 41.1 & 5.5 & 2.1 \\
\hline \multicolumn{4}{|l|}{ Admission Ferritin $^{\mathrm{d}}(\mathrm{ng} / \mathrm{mL})$} \\
\hline $0-499$ & 44.8 & 4.9 & 2.4 \\
\hline $500-999$ & 13.2 & 1.9 & 0.8 \\
\hline$\geq 1000$ & 11.1 & 2.1 & 1.7 \\
\hline Unmeasured & 30.9 & 4.3 & 1.5 \\
\hline \multicolumn{4}{|l|}{ Admission $\mathrm{CRP}^{\mathrm{c}}(\mathrm{mg} / \mathrm{L})$} \\
\hline 0-99 & 55.6 & 6.8 & 3.2 \\
\hline $100-199$ & 13.4 & 2.6 & 1.3 \\
\hline$\geq 200$ & 4.5 & 0.9 & 0.8 \\
\hline Unmeasured & 26.6 & 2.8 & 1.1 \\
\hline \multicolumn{4}{|l|}{ Charlson Score $^{\mathrm{e}}$} \\
\hline $0-2$ & 43.5 & 3.4 & 2.1 \\
\hline $3-5$ & 31.6 & 4.7 & 2.3 \\
\hline$\geq 6$ & 24.9 & 5.1 & 2.1 \\
\hline Atrial Fibrillation & 10.0 & 1.9 & 0.8 \\
\hline Coronary Artery Disease ${ }^{b}$ & 4.1 & 1.1 & 0.4 \\
\hline Congestive Heart Failure & 12.2 & 2.4 & 1.1 \\
\hline Diabetes Mellitus & 32.4 & 5.5 & 2.6 \\
\hline Connective Tissue Disorders & 2.8 & 0.4 & 0.2 \\
\hline COPD & 8.9 & 1.5 & 0.8 \\
\hline Liver Failure ${ }^{\mathrm{c}, \mathrm{e}}$ & 1.1 & 0.6 & 0.4 \\
\hline HIV & 0.8 & 0.0 & 0.0 \\
\hline Hypertension & 58.8 & 8.3 & 4.3 \\
\hline Leukemia or Lymphoma & 9.0 & 1.7 & 0.9 \\
\hline Other Immunodeficiencies & 0.8 & 0.4 & 0.0 \\
\hline Peripheral Artery Disease & 3.6 & 0.8 & 0.0 \\
\hline
\end{tabular}


Table 1 (continued)

\begin{tabular}{llll}
\hline Characteristics & $\begin{array}{l}\text { All Patients } \\
(n=531) \%^{*}\end{array}$ & $\begin{array}{l}\text { Nasal Cannula } \\
(n=70) \%^{*}\end{array}$ & $\begin{array}{l}\text { Advanced Oxygenation } \\
\text { Therapy }(n=34) \%^{*}\end{array}$ \\
\hline Renal Disease $^{\mathrm{b}}$ & 19.0 & 3.6 & 1.5 \\
Solid Tumor $^{\text {Transplant }}$ & 4.0 & 0.4 & 0.4 \\
\hline
\end{tabular}

${ }^{\mathrm{a}} p<0.0001$ for nasal cannula and advanced oxygenation therapy

${ }^{\mathrm{b}} p<0.1$ for nasal cannula

${ }^{c} p<0.1$ for advanced oxygenation therapy

${ }^{\mathrm{d}} p<0.05$ for advanced oxygenation therapy

${ }^{\mathrm{e}} p<0.05$ for nasal cannula

*All percent values are row percents relative to all patients $(n=531)$

\section{Discussion}

Our study shows that the presence of exertional hypoxia in absence of resting hypoxia is strongly associated with the subsequent development of moderate to severe COVID-19, as determined by increasing oxygen support. In our patient population, exertional hypoxia occurred several hours before the need for $\mathrm{NC}$ and approximately 2 days prior to advanced oxygen therapies. This early warning sign may be useful for clinicians to recognize which patients are at greatest risk for clinical deterioration and therefore may also benefit from earlier initiation of treatments such as remdesivir [7] and/or dexamethasone [8]. It may also help health systems effectively identify patients most likely to require ICU-level care, which may improve hospital throughput, especially when hospitals are near or at capacity. It is also important to highlight the pragmatic nature of information acquisition, which occurred at bedside, non-invasively, at no cost, and produced robust results.

Exertional oximetry has been used to help determine severity of cardiopulmonary diseases including heart failure [9], pulmonary hypertension [10], chronic obstructive pulmonary disease [11], and interstitial lung disease [12]. To our knowledge, the presence of exertional hypoxia has never been shown to acutely predict cardiopulmonary disease progression. Several authors have suggested using a 6-min walk test to evaluate for disease severity in COVID19 , but did not provide data showing benefit $[13,14]$. Additionally, current guidelines suggest using exertional oximetry measurements as a risk assessment strategy in patients presenting to the emergency department with COVID-19 despite limited evidence [3, 4]. A recently published study of emergency department patients with suspected COVID-19 evaluated the association of the delta change in post-exertional oxygen saturations compared to resting saturations with 30 day adverse outcomes (death or need for organ support) [15]. After excluding patients in whom "post-exertion measurement appeared inappropriate" the authors showed a positive association between post-exertional desaturation and adverse outcomes [15]. This study differs from ours in several important ways: (1) we deliberately measured exertional saturations daily in hospitalized patients per hospital protocol; (2) we did not use a delta change for exertional hypoxia and instead used any $\mathrm{SpO} 2<90 \%$ on room air as this estimates $\mathrm{PaO} 2<60$ torr which defines hypoxemia (it is possible that using the delta change did not capture patients with $\mathrm{SpO} 2<90 \%$ ); and (3) we measured near-term outcomes including need for supplemental oxygen therapy. Furthermore, we demonstrated the median time difference between presentation of exertional hypoxia and use of oxygen therapies.

Additionally, other authors have advocated for exertional oximetry measurements to evaluate patients for discharge readiness after resolution of COVID-19 symptoms [16], a strategy already adopted in our hospital. A small study evaluated 47 patients with COVID-19 prior to hospital discharge with the 6-min walk test and found the test useful to screen for asymptomatic hypoxia [17]. This study did not evaluate clinical outcomes associated with exertional hypoxia due to small sample size, but showed that exertional hypoxia did allow diagnosis of venous thromboembolism in 4 patients that may have otherwise gone undetected [17].

Our current study adds to the growing body of evidence showing the usefulness of measuring exertional hypoxia in patients with COVID-19. We present the first study demonstrating exertional hypoxia predicts worsening pulmonary disease in patients hospitalized with COVID-19 and the median time difference between appearance of exertional hypoxia and need for oxygen therapy. We believe that exertional hypoxia (when present before resting hypoxia) should be used to guide admission or delay discharge in patients with acute COVID-19.

Our study has several limitations. First our study was performed at one health network with a relatively small number of patients potentially limiting generalizability. However, the associations between exertional hypoxia and worsening oxygenation were highly statistically significant. Second, we excluded patients who did not have exertional 
Table 2 Baseline Demographic and Clinical Characteristics of Patients in Whom Exertional Hypoxia was Detected

\begin{tabular}{ll}
\hline Characteristics & Patients with \\
& exertional hypoxia \\
& $(n=132) \%$ \\
\hline
\end{tabular}

Age (years)

$<50 \quad 22.7$

$50-59 \quad 22.7$

60-69 21.2

$\geq 70 \quad 33.3$

Sex

Male $\quad 50.8$

Female $\quad 49.2$

Race and Ethnicity

Non-Hispanic White $\quad 38.6$

Hispanic or Latino $\quad 31.1$

Black or African American 22

Other Races and ethnicities $\quad 8.3$

BMI $\left(\mathrm{kg} / \mathrm{m}^{2}\right)$

$<24.9$

22.7

$25.0-29.9$

26.5

$30.0-39.9$

32.6

11.4

Unmeasured

6.8

Admission D-Dimer (ng/mL)

0-999

62.1

$\geq 1000$

Unmeasured

6.8

31.1

Admission Ferritin (ng/mL)

$0-499$

41.7

500-999

17.4

$\geq 1000$

19.7

Unmeasured

21.2

Admission CRP (mg/L)

0-99

49.2

100-199

$\geq 200$

22

10.6

Unmeasured

18.2

Charlson Score

$0-2$

39.4

$3-5 \quad 30.3$

$\geq 6 \quad 30.3$

Atrial Fibrillation $\quad 10.6$

Coronary Artery Disease $\quad 8.3$

Congestive Heart Failure $\quad 15.9$

Diabetes Mellitus $\quad 33.3$

Connective Tissue Disorders $\quad 5.3$

COPD $\quad 9.8$

Liver Failure $\quad 2.3$

HIV 0

Hypertension $\quad 63.6$

Leukemia or Lymphoma $\quad 11.4$
Table 2 (continued)

\begin{tabular}{ll}
\hline Characteristics & $\begin{array}{l}\text { Patients with } \\
\text { exertional hypoxia } \\
(n=132) \%\end{array}$ \\
\hline Other Immunodeficiencies & 0.8 \\
Peripheral Artery Disease & 3.8 \\
Renal Disease & 19.7 \\
Solid Tumor & 4.5 \\
Transplant & 3 \\
\hline
\end{tabular}

oximetry measurements. Exertional oxygen measurement is part of the admission order protocols in our health system, so patients without measurements likely represented a sicker cohort unable to ambulate or those with mild disease who were discharged quickly. Patients without measurement may also have been cared for by clinicians who did not order exertional oximetry. Third, we did not directly measure the presence of resting hypoxia because it was often not documented in the medical record before the use of oxygen therapy. The use of oxygen therapy was used as a surrogate for resting hypoxia. We decided to use oxygen therapy as a surrogate because patients are more likely to be on oxygen without hypoxia rather than left to be hypoxic on room air without supplemental oxygen. Application of oxygen without hypoxia would skew time of use of oxygen therapy earlier. If some patients were left hypoxic before documenting use of oxygen therapy, the time measurements of detecting resting hypoxia in our study would be skewed later. Despite this, there remained a significant amount of time between development of exertional hypoxia and use of supplemental or advanced oxygen therapies. Fourth, we excluded all patients who used oxygen therapy before exertional oximetry measures. These patients likely underwent exertional oximetry to determine discharge readiness. Alternatively, there may have been a small number of these patients who were given NC treatment for subjective comfort without resting hypoxia, who then developed exertional hypoxia. The exclusion criteria we applied to select our patients resulted in a purer sample: patients truly not on any oxygen at time of admission who then eventually required it in the hospital. Finally, all measurements occurred in-room, which may not have provided ample space for patients to fully exert themselves, and some patients may have terminated the test early due to fatigue or intolerance with or without development of exertional hypoxia. However, $24.9 \%(n=132)$ of patients still were identified with exertional hypoxia.

Future prospective studies should be performed to evaluate earlier interventions in patients with COVID-19 and exertional hypoxia without resting hypoxia. An important extension of our findings could be the use of exertional oximetry measurement in triaging outpatients, emergency department patients, and inpatients with COVID-19. 
Table 3 Multiple Logistic and Poisson Regression Results for the Association of Exertional Hypoxia with the likelihood of Nasal Cannula or Advanced Oxygenation use in 531 Inpatients with COVID-19

\begin{tabular}{|c|c|c|c|c|}
\hline \multirow[t]{2}{*}{ Characteristics } & \multicolumn{2}{|l|}{ Nasal Cannula } & \multicolumn{2}{|c|}{ Advanced Oxygenation } \\
\hline & OR $(95 \% \mathrm{CI})$ & $p$ & IRR (95\% CI) & $p$ \\
\hline Exertional Hypoxia Present & $4.8(2.8-8.4)$ & $3 \times 10^{-8}$ & $7.7(3.4-17.5)$ & $8 \times 10^{-7}$ \\
\hline \multicolumn{5}{|l|}{ Age (years) } \\
\hline$<50 *$ & - & - & - & - \\
\hline $50-59$ & $1.5(0.6-3.6)$ & 0.40 & $1.0(0.3-3.2)$ & 0.97 \\
\hline $60-69$ & $1.2(0.4-3.1)$ & 0.75 & $1.7(0.5-6.2)$ & 0.40 \\
\hline$\geq 70$ & $0.6(0.2-1.8)$ & 0.35 & $0.9(0.2-4.1)$ & 0.88 \\
\hline \multicolumn{5}{|l|}{ Gender } \\
\hline Male & $0.8(0.5-1.4)$ & 0.47 & $1.6(0.7-3.6)$ & 0.23 \\
\hline Female* & - & - & - & - \\
\hline \multicolumn{5}{|l|}{ Race and Ethnicity } \\
\hline Non-Hispanic White* & - & - & - & - \\
\hline Hispanic or Latino & $0.8(0.4-1.7)$ & 0.62 & $0.9(0.3-2.5)$ & 0.85 \\
\hline Black or African American & $0.4(0.2-0.9)$ & 0.02 & $1.3(0.5-3.4)$ & 0.59 \\
\hline Other Races and ethnicities & $1.0(0.4-2.6)$ & 0.98 & $2.1(0.6-6.7)$ & 0.23 \\
\hline \multicolumn{5}{|l|}{ BMI $\left(\mathrm{kg} / \mathrm{m}^{2}\right)$} \\
\hline$<25.0^{*}$ & - & - & - & - \\
\hline $25.0-29.9$ & $1.0(0.5-2.2)$ & 0.95 & $0.7(0.2-1.9)$ & 0.48 \\
\hline $30.0-39.9$ & $1.0(0.5-2.3)$ & 0.91 & $0.8(0.3-2.2)$ & 0.64 \\
\hline$\geq 40$ & $2.3(0.9-6.2)$ & 0.10 & $2.6(0.8-7.9)$ & 0.10 \\
\hline Unmeasured & $1.1(0.3-3.4)$ & 0.87 & $0.7(0.1-3.5)$ & 0.65 \\
\hline \multicolumn{5}{|l|}{ Admission CRP (mg/L) } \\
\hline$<100 *$ & - & - & - & - \\
\hline 100-199 & - & - & $1.9(0.8-4.5)$ & 0.96 \\
\hline$\geq 200$ & - & - & $1.7(0.7-4.1)$ & 0.81 \\
\hline Unmeasured & - & - & $1.1(0.4-2.9)$ & 0.68 \\
\hline \multicolumn{5}{|l|}{ Admission Ferritin(ng/mL) } \\
\hline$<500^{*}$ & - & - & - & - \\
\hline $500-999$ & - & - & $1.5(0.5-4.7)$ & 0.94 \\
\hline$\geq 1000$ & - & - & $0.9(0.3-2.6)$ & 0.28 \\
\hline Unmeasured & - & - & $1.1(0.3-3.5)$ & 0.77 \\
\hline \multicolumn{5}{|l|}{ Charlson Score } \\
\hline$<3^{*}$ & - & - & - & - \\
\hline $3-5$ & $2.4(1.1-5.5)$ & 0.03 & $1.4(0.5-3.9)$ & 0.55 \\
\hline$\geq 6$ & $4.6(1.8-12.3)$ & 0.002 & $1.4(0.4-5.1)$ & 0.63 \\
\hline
\end{tabular}

*Denotes reference category

Exertional hypoxia in absence of resting hypoxia may help determine whether admission and inpatient monitoring with continuous pulse oximetry is warranted.

Supplementary Information The online version contains supplementary material available at https://doi.org/10.1007/s11739-021-02708-w.

Author contribution All authors had access to the data, a role in writing, reviewing, and approving the manuscript.

Funding Not applicable.

Data availability Data available upon reasonable request.

\section{Declarations}

Conflict of interest To the best of our knowledge, no conflict of interest, financial or other, exists for authors contributing to this report.

Ethics approval The study was approved by the Northwestern University Institutional Review Board.

Ethics Approval and Consent to participate This research study was conducted retrospectively from data obtained for clinical purposes that were part of the routine standard of care and was approved by the IRB of Northwestern University. Due to the retrospective nature of the study which occurred with stored data in the data warehouse, the IRB granted a waiver of consent. 


\section{References}

1. Dong E, Du H, Gardner L (2020) An interactive web-based dashboard to track COVID-19 in real time. Lancet Infect Dis 20(5):533-534. https://doi.org/10.1016/S1473-3099(20)30120-1

2. Wang Y, Dong C, Hu Y, Li C, Ren Q, Zhang X, Shi H, Zhou M (2020) Temporal changes of CT findings in 90 patients with COVID-19 pneumonia: a longitudinal study. Radiology 296(2):E55-E64. https://doi.org/10.1148/radiol.2020200843

3. Emergency Department COVID-19 Severity Classi-cation. https:// www.acep.org/globalassets/sites/acep/media/covid-19-main/acep_ evidencecare covid19severitytool.pdf. Accessed 1/3/2021

4. Edward H. Suh LA, David Bodnar, Gerardo Chiricolo, Nicholas Gavin, Jonathon LeBaron, Laura Melville, Marie-Laure Romney, Manish Sharma, Amos J. Shemesh, Peter A.D. steel, Brenna M. Farmer (2020) ACEP COVID-19 Field Guide: Evaluation Pathway for Patietns with Possible COVID-19. https://www.acep.org/ corona/covid-19-field-guide/risk-stratification/evaluation-pathw ay-for-patients-with-possible-covid-19/. Accessed 1/3/2021

5. Zhang J, Yu KF (1998) What's the relative risk? A method of correcting the odds ratio in cohort studies of common outcomes. JAMA 280(19):1690-1691. https://doi.org/10.1001/jama.280.19. 1690

6. Zou G (2004) A modified poisson regression approach to prospective studies with binary data. Am J Epidemiol 159(7):702-706. https://doi.org/10.1093/aje/kwh090

7. Beigel JH, Tomashek KM, Dodd LE, Mehta AK, Zingman BS, Kalil AC, Hohmann E, Chu HY, Luetkemeyer A, Kline S, Lopez de Castilla D, Finberg RW, Dierberg K, Tapson V, Hsieh L, Patterson TF, Paredes R, Sweeney DA, Short WR, Touloumi G, Lye DC, Ohmagari N, Oh MD, Ruiz-Palacios GM, Benfield T, Fatkenheuer G, Kortepeter MG, Atmar RL, Creech CB, Lundgren J, Babiker AG, Pett S, Neaton JD, Burgess TH, Bonnett T, Green M, Makowski M, Osinusi A, Nayak S, Lane HC, Members A-SG (2020) Remdesivir for the treatment of Covid-19-final report. N Engl J Med 383(19):1813-1826. https://doi.org/10.1056/NEJMo a2007764

8. Group RC, Horby P, Lim WS, Emberson JR, Mafham M, Bell JL, Linsell L, Staplin N, Brightling C, Ustianowski A, Elmahi E, Prudon B, Green C, Felton T, Chadwick D, Rege K, Fegan C, Chappell LC, Faust SN, Jaki T, Jeffery K, Montgomery A, Rowan K, Juszczak E, Baillie JK, Haynes R, Landray MJ (2020) Dexamethasone in hospitalized patients with Covid-19 - preliminary report. N Engl J Med. https://doi.org/10.1056/NEJMoa2021436

9. Gheorghiade M, Follath F, Ponikowski P, Barsuk JH, Blair JE, Cleland JG, Dickstein K, Drazner MH, Fonarow GC, Jaarsma T, Jondeau G, Sendon JL, Mebazaa A, Metra M, Nieminen M, Pang PS, Seferovic P, Stevenson LW, van Veldhuisen DJ, Zannad F,
Anker SD, Rhodes A, McMurray JJ, Filippatos G, European Society of C, European Society of Intensive Care M (2010) Assessing and grading congestion in acute heart failure: a scientific statement from the acute heart failure committee of the heart failure association of the European Society of Cardiology and endorsed by the European Society of Intensive Care Medicine. Eur J Heart Fail 12(5):423-433. https://doi.org/10.1093/eurjhf/hfq045

10. Rubin LJ (2012) The 6-minute walk test in pulmonary arterial hypertension: how far is enough? Am J Respir Crit Care Med 186(5):396-397. https://doi.org/10.1164/rccm.201206-1137ED

11. Stoller JK, Panos RJ, Krachman S, Doherty DE, Make B, Longterm Oxygen Treatment Trial Research G (2010) Oxygen therapy for patients with COPD: current evidence and the long-term oxygen treatment trial. Chest 138(1):179-187. https://doi.org/10. 1378/chest.09-2555

12. Khor YH, Goh NS, Glaspole I, Holland AE, McDonald CF (2019) Exertional desaturation and prescription of ambulatory oxygen therapy in interstitial lung disease. Respir Care 64(3):299-306. https://doi.org/10.4187/respcare.06334

13. Noormohammadpour P, Abolhasani M (2020) Besides other signs, can a 6-min walk test be applied as a criterion for going to the hospital with a diagnosis of COVID-19? Adv J Emerg Med. https:// doi.org/10.22114/ajem.v0i0.387

14. Pandit R, Vaity C, Mulakavalupil B, Matthew A, Sabnis K, Joshi S (2020) Unmasking Hypoxia in COVID 19 - Six Minute Walk Test. J Assoc Physicians India 68(9):50-51

15. Goodacre S, Thomas B, Lee E, Sutton L, Loban A, Waterhouse S, Simmonds R, Biggs K, Marincowitz C, Schutter J, Connelly S, Sheldon E, Hall J, Young E, Bentley A, Challen K, Fitzsimmons C, Harris T, Lecky F, Lee A, Maconochie I, Walter D (2020) Post-exertion oxygen saturation as a prognostic factor for adverse outcome in patients attending the emergency department with suspected COVID-19: a substudy of the PRIEST observational cohort study. Emerg Med J. https://doi.org/10.1136/emerm ed-2020-210528

16. Hussain T, Saman HT, Yousaf Z (2020) Identification of Exertional Hypoxia and Its Implications in SARS-CoV-2 Pneumonia. Am J Trop Med Hyg 103(4):1742-1743. https://doi.org/10.4269/ ajtmh.20-1012

17. Fuglebjerg NJU, Jensen TO, Hoyer N, Ryrso CK, Lindegaard B, Harboe ZB (2020) Silent hypoxia in patients with SARS CoV-2 infection before hospital discharge. Int J Infect Dis 99:100-101. https://doi.org/10.1016/j.ijid.2020.07.014

Publisher's Note Springer Nature remains neutral with regard to jurisdictional claims in published maps and institutional affiliations. 